\title{
High sustained viral response among HCV genotype 3 patients with advanced liver fibrosis - real-world data of HCV elimination program in Georgia
}

Maia Butsashvili ( $\square$ maiabutsashvili@gmail.com )

Clinic NEOLAB

Lia Gvinjilia

CDC Foundation

George Kamkamidze

Health Research Union

David Metreveli

Medical Center Mrcheveli

Shorena Dvali

Infectious Diseases, AIDS and Clinical Immunology Center

Tamar Rukhadze

Clinic Hepa

\section{Amiran Gamkrelidze}

National Center for Disease Control and Public Health

\section{Muazzam Nasrullah}

Division of Viral Hepatitis, National Center for HIV/AIDS, Viral Hepatitis, STD and TB Prevention, CDC

\section{Shaun Shadaker}

Division of Viral Hepatitis, National Center for HIV/AIDS, Viral Hepatitis, STD and TB Prevention, CDC Juliette Morgan

Epidemiology, Informatics, Surveillance and Laboratory Branch (EISLB), Division of Global Health Protection (DGHP), Center for Global Helath (CGH), CDC

\section{Francisco Averhoff}

Division of Viral Hepatitis, National Center for HIV/AIDS, Viral Hepatitis, STD and TB Prevention, CDC

Research article

Keywords: HCV, SVR, genotype 3, fibrosis, liver, elimination

Posted Date: December 9th, 2019

DOI: https://doi.org/10.21203/rs.2.18492/v1 
License: (c) (i) This work is licensed under a Creative Commons Attribution 4.0 International License. Read Full License

Version of Record: A version of this preprint was published at BMC Research Notes on July 11th, 2020. See the published version at https://doi.org/10.1186/s13104-020-05173-4. 


\section{Abstract}

Background: In 2015, Georgia launched world's first HCV elimination program. Initially, patients with advanced liver disease were prioritized to receive sofosbuvir-based treatment regimen, as it was the only DAA available for all genotypes. Purpose of the study was to assess real-world data of treatment outcome among patients with HCV GEN3 and advanced liver fibrosis with sofosbuvir-based regimens.

Methods: GEN3 patients enrolled in the program, received sofosbuvir-based regimens, and had outcome data from April 28 through September 30, 2016 were eligible for the study. Demographic and clinical data were analyzed.

Results: A total of 1525 genotype 3 patients were eligible for analysis; most $(72.6 \%)$ were aged $>45$ years, majority were males (95.1\%), and all (100\%) had advanced liver disease (F3 or F4 by METAVIR score based on elastography). Of those who received sofosbuvir/ribavirin (SOF/RBV) for 24 weeks, 449/566 (79.3\%) achieved SVR, while 925/959 (96.5\%) who received sofosbuvir/pegylated interferon/ribavirin (SOF/PEG/RBV) for 12 weeks achieved SVR ( $p<.01)$. Among patients with liver cirrhosis (defined as F4) overall cure rate was $85.7 \%$ as opposed to $96.4 \%$ for those with F3. Females were more likely to be cured (98.7\% vs $89.7 \%$; OR=8.54, 95\%Cl:1.18-61.87). Patients aged 31-45 years had higher likelihood of achieving SVR compared to patients aged $46-60$ years (95.7\% vs $87.4 \%$; OR=0.32, 95\% Cl:0.19-0.53). Independent predictors of SVR were treatment with SOF/PEG/RBV (aOR=6.72, 95\%Cl:4.49-10.06) and lower fibrosis stage (F3) (aOR=4.18, 95\% Cl:2.64-6.61).

Conclusions: Real-world experience among HCV GEN3 patients with advanced liver fibrosis and treated by sofosbuvir regimen w/o PEGIFN, demonstrated overall high SVR rate.

\section{Background}

The World Health Organization (WHO) estimates, globally 71 million people are living with chronic hepatitis $\mathrm{C}$ virus (HCV) infection, and 400,000 die annually, mostly from complications of cirrhosis and hepatocellular carcinoma (1). Recently introduced direct-acting antivirals (DAAs) offer an opportunity for curing the vast majority of infected persons, which will reduce the transmission risk and prevalence of $\mathrm{HCV}$ in the population.

Georgia has a high burden of HCV infection; a 2015 national serosurvey found that an estimated $5.4 \%$ of adults are currently infected with HCV (2). On April 28, 2015, Georgia launched the world's first National HCV Elimination Program that included free of charge treatment with DAAs for all HCV infected persons (3). The DAAs for the elimination program are donated by Gilead Sciences, and sofosbuvir was the first DAA available for the program. In the initial phase of the program, patients with moderate or severe liver disease were prioritized to receive treatment (3). Cure rates for HCV infection (i.e., Sustained Virologic Response or SVR) varies depending on the genotype, degree of liver fibrosis, and the specific DAAs used (4-11). HCV infected patients with genotype 3 are considered difficult to treat with DAAs, compared to other genotypes $(5,12,13)$. 
The HCV elimination treatment program in Georgia, with a large number of patients with genotype 3 patients offers a unique opportunity to study the outcomes among these hard to treat patients in a realworld setting. We aimed to study the real-world treatment outcomes among genotype $3 \mathrm{HCV}$ infected patients with advanced disease treated with sofosbuvir (SOF)-based regimens.

\section{Methods}

The Georgia National HCV Elimination Program collects data on enrolled patients' pre-treatment, during treatment, and post treatment. Data collected includes socio-demographic information, clinical and laboratory data, and prescribed medications based on national guidelines upon enrolment. These data are collected using standardized protocols, and entered into a national treatment database, STOP-C, developed for the HCV elimination program. Data collected and stored in STOP-C includes HCV genotype and viral load, level of liver fibrosis, risk factors for HCV infection and treatment-related laboratory data, including SVR at week 12-24 after completion of treatment.

Data from April 28, 2015 through September 30, 2016 from STOP-C were analysed. Characteristics and outcomes of patients with genotype 3 were extracted. Only patients with advanced fibrosis (F3 or F4 by METAVIR score based on elastography) who had SOF-based regimens and valid SVR 12-24 results were included in the analysis. The treatment for patients with genotype 3 per national guidelines, was either sofosbuvir and ribavirin (SOF/RBV) for 24 weeks, or sofosbuvir, ribavirin and pegylated interferon (PEG IFN) $2 a$ or $2 b(S O F / P E G / R B V)$ for 12 weeks, depending on patient eligibility to receive IFN. Treatment outcomes were analysed by degree of liver fibrosis (F4-cirrhosis vs F3-non-cirrhosis) and treatment regimen. Statistical software, SAS version 9.4, was used for data analysis. Bivariate associations between treatment outcome with different factors, such as treatment regimen, fibrosis stage, age, and gender were analysed using chi-square. Multivariate analysis with logistic regression was used to estimate odds ratios adjusted for age and gender (aORs) and define independent predictors of SVR.

\section{Results}

A total of 1525 genotype 3 patients completed their SOF-based treatment and had an SVR result available for analysis (Table 1). The overall cure rate i.e., SVR for the genotype 3 patients was $90.1 \%$ (1374/1525). Among patients with liver cirrhosis (F4 by elastography) the overall cure rate was $85.7 \%$ (764/892) as compared to non-cirrhotic patients (F3 or F3/F4) where 610/633 (96.4\%) achieved SVR. The SVR rate was significantly higher among those treated with SOF/INF/RBV containing regimen compared to those ineligibles for prescribing interferon-based treatment. Out of 959 patients receiving PEG IFN 2a or 2b with SOF and RBV for 12 weeks, 925 (96.5\%) achieved SVR compared to 79.3\% cure rate among those treated with SOF and RBV for 24 weeks (449 out of 566). 
Table 1

Sustained virologic response (SVR) by age, gender and fibrosis stage $(N=1525)$, nationwide HCV elimination program, Georgia, April 28, 2015-September 30, 2016

\begin{tabular}{|c|c|c|c|c|}
\hline & $\begin{array}{l}\text { Total } n \\
(\%) \\
N=1525\end{array}$ & $\begin{array}{l}\text { SVR achieved } n \\
(\%) \\
N=1374\end{array}$ & $\begin{array}{l}\text { Unadjusted OR and } \\
95 \% \mathrm{Cl}\end{array}$ & $\begin{array}{l}\text { Adjusted OR and } \\
95 \% \mathrm{Cl}\end{array}$ \\
\hline $\begin{array}{l}\text { Age group } \\
18-30 \\
31-45 \\
46-60 \\
>60\end{array}$ & $\begin{array}{l}7 \\
411 \\
986 \\
121\end{array}$ & $\begin{array}{l}7(100.00) \\
393(95.62) \\
862(87.42) \\
112(92.56)\end{array}$ & $\begin{array}{l}\overline{-} \\
0.32(0.19,0.53) \\
0.57(0.25,1.30)\end{array}$ & \\
\hline $\begin{array}{l}\text { Gender } \\
\text { Male } \\
\text { Female }\end{array}$ & $\begin{array}{l}1450 \\
75\end{array}$ & $\begin{array}{l}1300(89.66) \\
74(98.67)\end{array}$ & $\begin{array}{l}1 \\
8.54(1.18,61.87)\end{array}$ & \\
\hline $\begin{array}{l}\text { Fibrosis stage } \\
\text { F4 } \\
\text { F3 or F3/F4 }\end{array}$ & $\begin{array}{l}892 \\
633\end{array}$ & $\begin{array}{l}764(85.65) \\
610(96.37)\end{array}$ & $\begin{array}{l}1 \\
4.44(2.82,7.01)\end{array}$ & $\begin{array}{l}1 \\
4.18(2.64,6.61)\end{array}$ \\
\hline $\begin{array}{l}\text { Treatment } \\
\text { regimen } \\
\text { SOF/RBV } \\
\text { SOF/INF/RBV }\end{array}$ & $\begin{array}{l}566 \\
959\end{array}$ & $\begin{array}{l}449(79.33) \\
925(96.45)\end{array}$ & $\begin{array}{l}1 \\
7.09 \\
(4.76,10.56)\end{array}$ & $\begin{array}{l}1 \\
6.72(4.49,10.06)\end{array}$ \\
\hline
\end{tabular}

By bivariate analysis, gender was significantly associated with SVR rate. Females (74/75 [98.7\%] were more likely to be cured compared to males $1300 / 1450$ [89.7\%]; OR $=8.54,95 \% \mathrm{Cl}: 1.18-61.87$ ). Patients aged 31-45 years had higher chance of achieving SVR (95.7\% vs $87.4 \%$ ) compared to patients aged $46-$ 60 years $(\mathrm{OR}=0.32,95 \% \mathrm{Cl}: 0.19-0.53)$.

Multivariate analysis showed that the independent predictors of achieving SVR were treatment regimen (patients treated with SOF/IFN/RBV combination were more likely to be cured-aOR $=6.72,95 \% \mathrm{Cl}: 4.49-$ 10.06 ) and fibrosis stage (non-cirrhotic patients having higher chance of SVR-aOR $=4.18,95 \% \mathrm{Cl}: 2.64-$ 6.61). (Table 1).

\section{Discussion}

In this analysis of the real-world experience among HCV genotype 3 infected patients with advanced liver fibrosis treated with SOF containing regimen with or without pegylated interferon, we found patients achieved overall high SVR rates of $>90 \%$. Patients with liver cirrhosis in our cohort achieved higher SVR rates with this "first generation" DAA compared to previous published reports that enrolled cirrhotic patients with HCV genotype $3(13,14)$. Several studies demonstrated SVR rates of $60-70 \%$ among those receiving the SOF and RBV 24-week regimen $(6,14,15,16,17)$. The VALENCE trial reported an overall SVR rate of $85 \%$ among genotype 3 infected patients receiving the 24-week SOF/RBV regimen (6). In the VALENCE trial, SVR rates at 12-weeks post-treatment (SVR 12) were $91 \%$ for the non-cirrhotic group and 
$68 \%$ for the group of study participants with liver cirrhosis, and multivariate analysis identified the presence of liver cirrhosis as a predictor of non-response to treatment (6). Our cohort, which included only those with advanced liver disease, had a similar overall SVR rate as the one reported among patients without cirrhosis in the VALENCE study ( $90.12 \%$ vs $91 \%$ SVR rate).

Our report was limited to HCV infected genotype 3 patients with advanced liver disease. Also, the treatment outcomes were limited to two antiviral regimens: SOF/PEG/RBV and SOF/RBV. In June of 2016, sofosbuvir/ledipasvir (SOF/LED) was introduced in Georgia (2) and the treatment guidelines were modified to include this combination DAA, resulting in little to no PEG IFN use for treatment. The Georgia treatment guidelines differ from those of the American Association for the Study of Liver Diseases (AASLD) or The European Association for the Study of the Liver (EASL), providing a unique opportunity to observe population-based outcomes with alternative HCV treatment regimens. These results can inform clinicians and policy makers in countries with a large proportion or burden of HCV genotype 3 infection that may not have access to DAAs or combinations of DAAs that are available in high-income countries of North America and Western Europe.

It is hoped that pan-genotypic regimens will soon be introduced in Georgia, presenting the opportunity to greatly simplify testing and treatment regimens, supporting the realization of HCV Elimination in Georgia by 2020 (18).

\section{Conclusions}

In conclusion, high SVR rates can be achieved among patients with HCV genotype 3 and advanced liver fibrosis, particularly among those treated with a 12-week SOF/PEG/RBV regimen. This may inform treatment for HCV infected patients in countries with limited access to newer DAAs.

\section{Abbreviations}

HCV - hepatitis C virus

WHO - World Health Organization

DAAs - directly acting antivirals

SVR - sustained viral response

SOF - sofosbuvir

RBV - ribavirin

PEG - pegylated

INF - interferon 
aOR - adjusted odds ratio

LED - ledipasvir

AASLD - American Association for the Study of Liver Diseases

EASL - European Association for the Study of the Liver

\section{Disclaimer}

The findings and conclusions in this report are those of the authors and do not necessarily represent the views of the Centers for Disease Control and Prevention. The use of trade names is for identification only and does not imply endorsement by the Centres for Disease Control and Prevention.

\section{Declarations}

\section{Ethics approval and consent to participate}

The study was approved by the Institutional Review Board of Health Research Union (IRB00009520; IORG005619). Study participants were enrolled in the study after signing informed consent form specially developed for this study.

\section{Consent for publication}

Not applicable.

\section{Availability of data and materials}

The datasets used and/or analysed during the current study are available from the corresponding author on reasonable request.

\section{Competing interests}

The authors declare that they have no competing interests.

\section{Funding}

Not applicable

\section{Author's contributions}

MB was a major contributor in conception, design and writing of the manuscript. LG participated in interpretation of data and revision of the manuscript. GK contributed in analysis and interpretation of data. DM participated in data collection and revision of the manuscript. SD participated in data collection. TR participated in data collection. AG contributed in revision of the manuscript. MN 
contributed in conception, design and revision of the manuscript. SS participated in analysis and interpretation of data. JM contributed in revision of the manuscript. FA contributed in conception, design and revision of the manuscript. All authors read and approved the final manuscript.

\section{Acknowledgements}

Georgia HCV elimination program is conducted under the leadership from the Georgia Ministry of Labor, Health, and Social Affairs [MoLHSA] with strong stakeholder support, including partnership and technical assistance from CDC, and commitment from Gilead Sciences to donate direct-acting antiviral HCV medications (DAAs).

\section{References}

1. World Health Organization. Hepatitis C factsheet. No 164. Updated April, 2017.

2. Gvinjilia L, Nasrullah M, Sergeenko D, Tsertsvadze T, Kamkamidze G, Butsashvili M, et al. National Progress Toward Hepatitis C Elimination - Georgia, 2015-2016. MMWR Morb Mortal Wkly Rep 2016 Oct 21; 65(41):1132-1135.

3. Mitruka K, Tsertsvadze T,Butsashvili M, Gamkrelidze A, Sabelashvili P, Adamia E, et al. Launch of a Nationwide Hepatitis C Elimination Program-Georgia, April 2015. MMWR Morb Mortal Wkly Rep 2015 Jul 24; 64(28):753-7. Erratum in: MMWR Morb Mortal Wkly Rep. 2015 Jul 31; 64(29):806

4. Ampuero J, Reddy KR, Romero-Gomez M. Hepatitis C virus genotype 3: Meta-analysis on sustained virologic response rates with currently available treatment options. World Journal of Gastroenterology 2016; 22(22), 5285-5292.

5. Zoulim F, Liang TJ, Gerbes AL, Aghemo A, Deuffic-Burban S, Dusheiko G, et al . Hepatitis C virus treatment in the real world: optimising treatment and access to therapies. Gut 2015; 64(11):1824-33.

6. Zeuzem S, Dusheiko GM, Salupere R, Mangia A, Flisiak R, Hyland RH, Illeperuma A, Svarovskaia E, Brainard DM, Symonds WT, Subramanian GM, McHutchison JG, Weiland O, Reesink HW, Ferenci P, Hézode C, Esteban R; VALENCE Investigators.Sofosbuvir and ribavirin in HCV genotypes 2 and 3.N Engl J Med 2014; 370(21):1993-2001.

7. Ramos H, Linares P, Badia E, Martín I, Gómez J, Almohalla C, et al. Interferon-free treatments in patients with hepatitis $\mathrm{C}$ genotype 1-4 infections in a real-world setting. World J Gastrointest Pharmacol Ther 2017; 8(2):137-146.

8. Lawitz E,Mangia A, Wyles D, Rodriguez-Torres M, Hassanein T, Gordon SC, et al. Sofosbuvirfor previously untreated chronic hepatitis C infection. N Engl J Med 2013; 368(20):1878-87.

9. Galán RJ,Cidoncha EC,Martin MF, Rodriguez CC, Almeida CV, Verdugo RM. Antiviral regimen complexity index as an independent predictor of sustained virologic response in 
patients with chronic hepatitis C. J Manag Care Pharm 2013; 19(6):448-53

10. Parise ER,de Oliveira AC, Conceição RD, Amaral AC, Leite K. Responseto treatment with interferonalpha and ribavirin in patients with chronic Hepatitis $C$ virus genotypes 2 and 3 depends on the degree of hepatic fibrosis. Braz J Infect Dis 2006; 10(2):78-81.

11. Im GY,Dieterich DT. Direct-acting antiviral agents in patients with hepatitis $C$ cirrhosis. Gastroenterol Hepatol (N Y)2012; 8(11):727-65.

12. Pawlotsky JM. New hepatitis $C$ therapies: the toolbox, strategies, and challenges. Gastroenterology 2014; 146(5):1176-92.

13. Gondeau C, Pageaux GP, Larrey D. Hepatitis C virus infection: Are there still specific problems with genotype 3?World Journal of Gastroenterology 2015;21(42), 12101-12113.

14. Yang YM, Choi EJ. Efficacy and safety outcomes of sofosbuvir-based treatment regimens for hepatitis $C$ virus-infected patients with or without cirrhosis from phase III clinical trials. Ther Clin Risk Manag 2017; 13:477-497

15. IsakovV,Zhdanov K, Kersey K, Svarovskaia E, Massetto B, Zhu Y, et al. Efficacy of sofosbuvir plus ribavirin in treatment-naive patients with genotype- 1 and $-3 \mathrm{HCV}$ infection: results from a Russian Phase Illb study. Antivir Ther 2016; 21(8):671-678

16. FosterGR,Pianko S, Brown A, Forton D, Nahass RG, George J, et al; BOSON Study Group. Efficacy of sofosbuvir plus ribavirin with or without peginterferon-alfa in patients with hepatitis $C$ virus genotype 3 infection and treatment-experienced patients with cirrhosis and hepatitis $\mathrm{C}$ virus genotype 2 infection. Gastroenterology 2015; 149(6):1462-70.

17. JacobsonIM,Gordon SC, Kowdley KV, Yoshida EM, Rodriguez-Torres M, Sulkowski MS,et al; POSITRON Study; FUSION Study. Sofosbuvir for hepatitis C genotype 2 or 3 in patients without treatment options. N Engl J Med 2013; 368(20):1867-77.

18. Nasrullah M, Sergeenko D, Gvinjilia L, Gamkrelidze A, Tsertsvadze T, Butsashvili M, et al. The Role of Screening and Treatment in National Progress Toward Hepatitis C Elimination - Georgia, 2015-2016. MMWR Morb Mortal Wkly Rep 2017 Jul 28; 66(29):773-6. 